\title{
CARACTERIZAÇÃO E GÊNESE DE PERFIS PLÍNTICOS DESENVOLVIDOS DE ARENITO DO GRUPO BAURU. II - MINERALOGIA(1)
}

\author{
M. R. COELHO(2) \& P. VIDAL-TORRADO(3)
}

\begin{abstract}
RESUMO
Nas paisagens do norte e oeste do estado de São Paulo, plintita e petroplintita constituem feições que se repetem com freqüência sobre os arenitos cretácicos da Formação Adamantina (Grupo Bauru). Com o objetivo de avaliar as características mineralógicas desses materiais e estudar sua gênese, selecionaram-se dois perfis de solos representativos da paisagem local e constituídos por feições plínticas, petroplínticas e mosqueados. 0 estudo foi realizado na baixa meia encosta de uma vertente situada na Estação Experimental de Agronomia de Pindorama, do Instituto Agronômico (IAC), região norte do estado de São Paulo. Com base nas observações em microscópio de varredura e microanálise pontual realizadas em glébulas selecionadas, bem como nas análises mineralógicas da fração argila desferrificada e dos óxidos de ferro de todos os horizontes dos perfis estudados, constatou-se que caulinita, hematita e goethita são os princi pai s constituintes da fração argila dos nódulos e horizontes estudados. Os minerais mica, gi bbsita e anatásio complementam a mineralogia da fração argila das glébulas, assemelhando-se em constituição ao material interglebular eaos demais horizontes dos perfis. Quartzo, feldspatos potássicos, traços de feldspatos sódicos e ilmenita foram identificados como componentes da fração silte e areia dos nódulos. A presença constante de minerais alteráveis nas glébulas petroplínticas é evidência de que a gênese desses materiais está relacionada com a ferruginização do saprolito. Este fato, associado aos baixos teores de Al na estrutura dos óxidos de ferro das glébulas, evidencia sua formação em condições hidromórficas, supostamente relacionadas com a solubilização e mobilização do ferro ferroso, lixiviado da paisagem a montante e reprecipitado na zona de vadosa, onde os maiores potenciais de oxidação favoreceram a segregação e a preci pitação do ferro.
\end{abstract}

Termos de indexação: gênese de solos, petroplintita, plintita, óxidos de ferro, substituição isomórfica de Fe por Al.

\footnotetext{
(1) Parte da Tese de Mestrado do primeiro autor, apresentada ao curso de Pós-Graduação em Sol os e Nutrição de Plantas da E scola Superior de Agricultura "Luiz de Queiroz" - ESALQ/USP. Recebido para publicação em abril de 2002 e aprovado em março de 2003.

(2) Pesquisador do Centro Nacional de Pesquisa em Solos, E mbrapa Solos. Rua J ardim Botânico 1024, J ardim Botânico, CEP 22460000 Rio de J aneiro (RJ ). E-mail: mrcoelho@cnps.embrapa.br

(3) Professor do Departamento de Ciência do Solo, Escola Superior de Agricultura "Luiz de Queiroz" - ESALQ/USP. Caixa Postal 09, CEP 13.418-900 Piracicaba (SP). Bolsista do CNPq. E-mail: pablo@carpa.ciagri.usp.br
} 


\title{
SUMMARY: CHARACTERIZATION AND GENESIS OF PLINTHIC PROFILES DEVELOPED ON SANDSTONE (BAURU GROUP). II - MINERALOGICAL PROPERTIES
}

\begin{abstract}
In northern and western landscapes of São Paulo State, plinthite and petroplinthite are features observed commonly above the cretaceous Adamantina Formation sandstones (Bauru Group). Two representative soil profiles with plinthic, petroplinthic and mottling features were selected in the local landscape to eval uate the mineralogical characteristics and to study their formation. Thestudy was carried out at the foot of a mountainsidein the Experimental Station Pindorama of the Agronomic InstituteCampinas (IAC), in thenorth of São Paulo State, Brazil. Scanning microscopy and pontual microanalysis of selected glaebules, as well as the mineralogical analyses of the ironfree clay fraction and the iron oxides of all studied soil profiles were carried out. It was concluded that the main clay fraction minerals of the nodules and the soil are kaolinite, hematite, and goethite. Mica, gibbsite, and anataseal so contributeto themineral ogy of theclay fraction of thesegl aebules, being similar in composition to the surrounding soil material of the profiles. The silt and sand fraction of the nodules is composed by quartz, potassium fel dspars, traces of sodium fel dspars, and ilmenite. The constant presence of weatherabl emi neral s in the petroplinthic glaebules dearly indicates that theformation of thesefeatures was rel ated to iron segregation in thesaprolite. This phenomenon, associated with low levels of alumi num in thestructure of the gl aebules iron oxides suggests their formation under hydromorphic conditions. The hydromorphic environment is probably related to the solubilization and mobilization of ferrous iron that was removed from the upper landscape and preci pitated into the vadose zone, where oxidati ve conditions were favorable for iron segregation and preci pitation.
\end{abstract}

Index terms: soil genesis, petroplinthite, plinthite, laterite, iron oxides.

\section{NTRODUÇÃO}

Os estudos que avaliam a composição e as transformações mineralógicas dos materiais plínticos, petroplínticos e dos solos associados possibilitam um melhor entendimento da evolução dos sistemas de intemperismo já que os minerais são indicadores da extensão em que os diferentes processos têm atuado nas paisagens atuais.

Essas feições ferruginosas são de ocorrência comum nos solos sob domínio do Arenito Bauru, Formação Adamantina, regiões N orte e Oeste do estado de São Paulo. Distribuem-se em diferentes posições da paisagem, com variados padrões morfológicos e formas de ocorrência, refletindo a diversidade de processos pedogenéticos ocorrentes durante a evolução das paisagens atuais. Sua presença e diversificação das formas de ocorrência influem significativamente no comportamentofísicoquímico dos solos, fenômeno ainda pouco conhecido. Portanto, a dinâmica de formação e a evolução dos nódulos e dos sol os que desenvolvem essas feições, bem como as peculiaridades que afetam seu comportamento, devem ser el ucidadas para que se possa proceder ao uso e manejo adequados desses sol os (Batista \& Santos, 1995).

O presente trabalho objetiva caracterizar mineral ogicamenteas diferentes feições ferruginosas e os perfis onde ocorrem, fornecendo subsídios para elucidar alguns mecanismos envolvidos na gênese desses materiais. Para tanto, foram selecionados dois perfis de solos desenvolvidos de arenitos cretácicos da F ormação Adamantina, Grupo Bauru, elocalizados na baixa meia encosta de uma vertente representativa da paisagem local, caracterizada pela presença de plintita, petroplintita e mosqueados.

\section{MATERIAL E MÉTODOS}

\section{Meio físico}

O estudo foi realizado na Estação Experimental deAgronomia de Pindorama do InstitutoAgronômico (IAC), situada ao sul do município de Pindorama, entre as coordenadas geográficas de $21^{\circ} 13^{\prime}$ de latitude sul e $48^{\circ} 56^{\prime}$ de longitude oeste. Geologicamente, a região situa-se sob domínio do Grupo Bauru, Formação Adamantina (IPT, 1981), caracterizada por apresentar bancos de arenitos com granulaçãofina a muito fina, al ternados com lamitos, siltitos e arenitos lamíticos. São comuns nessa formação seixos de argilito, cimento e nódulos carbonáticos (Soares et al., 1980).

Segundo a classificação de Köppen, o clima da região enquadra-se como Aw, que é definido como 
tropical úmido, com estação chuvosa no verão eseca no inverno e com precipitação média anual de $1.390 \mathrm{~mm}$.

\section{Trabalho de campo}

F oram abertas duas trincheiras no segmento de vertente que melhor caracterizava as diferentes classes de solos. A descrição macro e a micromorfológica dos perfis estudados (perfis P1 e P2), bem como a ilustração da distribuição dos sol os na paisagem local, encontram-se em detalhes em Coel ho et al. (2001). No entanto, o quadro 1 evidencia a classificação, a seqüência de horizontes e alguns dos principais atributos morfológicos dos perfis $\mathrm{P} 1$ e P2.

\section{Análises laboratoriais}

As amostras de solo coletadas nas trincheiras foram secas ao ar, destorroadas com um martelo de borracha, passadas em peneira no 10 e submetidas às análises laboratoriais.

Amostras provenientes dos horizontes plínticos e petroplínticos foram submetidas ao penei ramento por via úmida em peneira n. ${ }^{\circ} 10$. Posteriormente, as glébulas foram individualmente escovadas em água corrente, secas ao ar, trituradas em moinho mecânico e passadas novamente em peneira o 10 . O solo entremeado aos nódulos plínticos e petroplínticos (matriz intergl ebular) foi seco ao ar e peneirado antes de ser submetido às determinações

\section{Quadro 1. Classificação e morfologia dos perfis estudados}

\begin{tabular}{|c|c|c|c|c|c|}
\hline Horizonte & Profundidade & Cor úmida & Textura & Estrutura & Consistência \\
\hline \multicolumn{6}{|c|}{$\mathrm{m}$} \\
\hline \multicolumn{6}{|c|}{ Perfil P1 - Plintossolo Pétrico Concrecionário distrófico típico, textura arenosa/média esquelética, A moderado(1) } \\
\hline A & $0,00-0,10$ & 7,5 YR 4/2 & Areia franca & $\begin{array}{l}\text { Moderada, pequena e média } \\
\text { blocos subangulares }\end{array}$ & $\begin{array}{l}\text { Macia, muito friável, } \\
\text { não-plástica e não pegajosa }\end{array}$ \\
\hline E & $0,10-0,25$ & 7,5 YR $4 / 4$ & Areia franca & $\begin{array}{l}\text { Fraca, média e grande, blocos } \\
\text { subangulares }\end{array}$ & $\begin{array}{l}\text { Ligeiramente dura, friável, } \\
\text { não-plástica e não-pegajosa }\end{array}$ \\
\hline $\mathrm{Cc}$ & $0,25-0,45$ & 5 YR 4/6 & $\begin{array}{l}\text { Franco-argilo- } \\
\text { arenosa }\end{array}$ & Matriz interglebular maciça & Plástica e pegajosa \\
\hline Cf & $0,45-0,55$ & $5 Y R 4 / 6$ & $\begin{array}{l}\text { Franco-argilo- } \\
\text { arenosa }\end{array}$ & Matriz interglebular maciça & Plástica e pegajosa \\
\hline $\mathrm{Cr}$ & $0,55-1,16$ & 2,5 YR 4/8 & $\begin{array}{l}\text { Franco-argilo- } \\
\text { arenosa }\end{array}$ & $\begin{array}{l}\text { Fragmentos de rocha } \\
\text { entremeados a uma matriz } \\
\text { terrosa maciça }\end{array}$ & $\begin{array}{l}\text { Dura, muito firme, plástica e } \\
\text { pegajosa }\end{array}$ \\
\hline Crg1 & $1,16-1,40$ & Variegada & $\begin{array}{l}\text { Franco-argilo- } \\
\text { arenosa }\end{array}$ & $\begin{array}{l}\text { Fragmentos de rocha } \\
\text { entremeados a uma matriz } \\
\text { terrosa maciça }\end{array}$ & $\begin{array}{l}\text { Ligeiramente dura, firme, } \\
\text { plástica e pegajosa }\end{array}$ \\
\hline Crg2 & $1,40-1,80$ & Variegada & Areia franca & $\begin{array}{l}\text { Fragmentos de rocha } \\
\text { entremeados a uma matriz } \\
\text { terrosa maciça }\end{array}$ & $\begin{array}{l}\text { Ligeiramente dura, firme, } \\
\text { ligeiramente plástica e } \\
\text { ligeiramente pegajosa }\end{array}$ \\
\hline \multicolumn{6}{|c|}{ Perfil P2 - Argissolo Vermelho-Amarelo eutrófico abrúptico plíntico, textura arenosa/média, A moderado } \\
\hline A & $0,00-0,10$ & 7,5 YR 4/2 & Areia franca & $\begin{array}{l}\text { Fraca, média, blocos } \\
\text { subangulares }\end{array}$ & $\begin{array}{l}\text { Macia, friável, não-plástica e } \\
\text { não-pegajosa }\end{array}$ \\
\hline E & $0,10-0,26$ & 7,5 YR $4 / 4$ & Areia franca & $\begin{array}{l}\text { Fraca, média, blocos } \\
\text { subangulares }\end{array}$ & $\begin{array}{l}\text { Ligeiramente dura, friável, não } \\
\text { plástica e não pegajosa }\end{array}$ \\
\hline Bt1 & $0,26-0,38$ & 5 YR 4/6 & $\begin{array}{l}\text { Franco-argilo- } \\
\text { arenosa }\end{array}$ & $\begin{array}{l}\text { Moderada, média e grande, blocos } \\
\text { subangulares }\end{array}$ & $\begin{array}{l}\text { Dura, firme, ligeiramente plástica } \\
\text { eligeiramente pegajosa }\end{array}$ \\
\hline Bt2 & $0,38-0,60$ & 5 YR 4/8 & $\begin{array}{l}\text { Franco-argilo- } \\
\text { arenosa }\end{array}$ & $\begin{array}{l}\text { Moderada, média e grande, blocos } \\
\text { subangulares }\end{array}$ & Dura, firme, plástica e pegajosa \\
\hline $\mathrm{Cc}$ & $0,60-0,85$ & $5 \mathrm{YR} 4 / 6$ & $\begin{array}{l}\text { Franco-argilo- } \\
\text { arenosa muito } \\
\text { cascal henta }\end{array}$ & Matriz maciça & Plástica e pegajosa \\
\hline $\mathrm{Cf}$ & $0,85-1,10$ & 5 YR 4/8 & $\begin{array}{l}\text { Franco-argilo- } \\
\text { arenosa muito } \\
\text { cascalhenta }\end{array}$ & Matriz maciça & Plástica e pegajosa \\
\hline $\mathrm{Cr}$ & $1,10-1,64$ & $2,5 Y R \quad 4 / 6$ & $\begin{array}{l}\text { Franco-argilo- } \\
\text { arenosa }\end{array}$ & $\begin{array}{l}\text { Estrutura original da rocha } \\
\text { entremeada a uma matriz terrosa } \\
\text { maciça }\end{array}$ & $\begin{array}{l}\text { Ligeiramente dura, firme, } \\
\text { plástica pegajosa }\end{array}$ \\
\hline $\mathrm{R}$ & $1,64-1,90$ & $2,5 Y R \quad 4 / 6$ & Franco-arenosa & Estrutura da rocha & $\begin{array}{l}\text { Dura, firme, ligeiramente plástica } \\
\text { eligeiramente pegajosa }\end{array}$ \\
\hline
\end{tabular}

(1) EMBRAPA (1999). 
analíticas. Apenas o horizonte plíntico do perfil P2 foi submetido aos procedimentos convencionais de preparo das amostras, ou seja, as glébulas e matriz foram homogeneizadas com martelo de borracha e passadas em peneira.

\section{Análises mineralógicas}

Mineralogia da fração argila desferrificada

Todo o preparo e tratamento das amostras para a determinação da composição mineralógica da fração argila desferrificada foram realizados de acordo comJ ackson (1969) e os minerais identificados, segundo Brown (1961). Os difratogramas de raios$X$ foram obtidos em aparel ho Philips, modelo PW 1010, dotado de tubo de ânodo de cobre, com filtro de níquel e com a unidade de força operando a $40 \mathrm{KV}$ e $20 \mathrm{~m} \AA$. A irradiação para os diferentes tratamentos foi de $3^{\circ}$ a $30^{\circ} 2 \theta$.

\section{Mineralogia dos óxidos de ferro}

Para a caracterização mineralógica dos óxidos de ferro, procedeu-se ao método descrito por N orrish \& Taylor (1961), modificado por Kämpf \& Schwertmann (1982). Os óxidos de ferro concentrados foram analisados por difratometria de raios-X (DRX). O difratômetro, equipado com tubo de cobalto e filtro de ferro, foi operado com a unidade de força a $26 \mathrm{~m} \AA$ e $36 \mathrm{KV}$, sendo a lâmina montada em pó com $30 \%$ de quartzo finamente moído.

\section{Estimativa da substituição isomórfica na} hematita (Hm) e goethita (Gt)

A determinação do grau de substituição isomórfica de Fe por Al nos óxidos de ferro foi realizada tanto por difratometria de raios- $X$, como por métodos químicos.

No primeiro caso, a substituição isomórfica foi determinada por meio de equações publicadas que relacionam o parâmetro unidade da cela unitária (posição dos reflexos obtidos por DRX) ao conteúdo de Al existente na estrutura dos óxidos de $\mathrm{Fe}$, segundo Schwertmann et al. (1979) eSchulze(1982).

No segundo, foram utilizadas duas equações desenvolvidas por Guillet \& J eanroy (1985) e Shadfan et al. (1985), as quais consideram os valores de ferro e alumínio extraídos com os reagentes ditionito-citrato (DC) eoxal ato-oxálico (dados obtidos de Coel ho \& Vidal-Torrado, 2003).

\section{Cálculo da relação $\mathbf{R}(\mathbf{H m} / \mathbf{H m}+\mathbf{G t})$}

A relação $R$ foi estimada com base nas áreas dos reflexos da $\mathrm{Hm}$ e Gt. A fórmula utilizada para cálculo foi sugerida por Resende et al. (1987).

\section{Cálculo dos conteúdos de $\mathbf{H m}$ e Gt}

Procedeu-se à estimativa quantitativa da mineralogia dos óxidos de ferro, utilizando-se o método da alocação proposto por Resende et al. (1987), modificado por Netto (1996). Os elementos químicos dos minerais extraídos pelo ataque sulfúrico e ditionito-citrato (DC) na fração argila, obtidos de Coelho \& Vidal-Torrado (2003), foram alocados nos minerais identificados por DRX.

\section{Análise submicroscópica e microanálise pontual}

Amostras indeformadas e selecionadas das glébulas plínticas e petroplínticas foram submetidas ao exame em microscópio el etrônico de varredura marca J EOL, model o J SM - T330A, equipado com microssonda NORAN, modelo TN 500.

\section{Análise granulométrica}

A distribuição dos separados do solo na fração menor que $2 \mathrm{~mm}$ foi determinada pelo método da pipeta, conforme recomendações de Camargo et al. (1986).

\section{Análises químicas e fluorescência de raios-X}

Os teores dealumíniotrocável foram determi nados segundo Camargo et al. (1986). As extrações seletivas de manganês seguiram as recomendações de Buurman et al. (1996). O cobre total foi determinado por fluorescência de raios-X em aparelho Philips, modelo PW 2400, utilizando-se amostras pulverizadas com granulometria inferior a 200 mesh e prensadas a $30 \mathrm{~T} \mathrm{~cm}^{-2} \mathrm{em} 25 \%$ de cera.

\section{RESULTADOS E DISCUSSÃO}

\section{Mineralogia da fração argila desferrificada}

$\mathrm{Na}$ figura 1, são apresentados os difratogramas deraios-X das petroplintitas (Cc-N) do perfil P1. As glébulas dos perfis analisados são mineralogicamente semel hantes (difratogramas não mostrados), apenas diferindo pela presença de traços de gibbsita nas amostras petroplínticas dos perfis observados.

Os dados constantes no quadro 2 evidenciam que teores similares de caulinita estão presentes nas glébulas plínticas e petroplínticas do perfil P1, porém o mineral encontra-se em menores proporções na petroplintita do P2. I sso revela a maior acumulação de ferro neste material (Coelho e Vidal-Torrado, 2003) supostamente responsável pela dissol ução da caul inita, à medida que o ferro é segregado durante a formação dos nódulos, tal como originalmente constatado por Muller \& Bocquier (1986).

Além desses minerais, mica é outro componente da fração argila das glébulas. Assim, caulinita, mica e, eventualmente, traços de gibbsita, são os mi nerais da fração argila das glébulas. Evidenciou-se a origem autigênica de parte dos minerais gi bbsíticos, e sua formação será discutida na interpretação dos resultados de microscopia el etrônica devarredura e microanálise pontual. 
Mineral ogia semel hanteàs gl ébulas foi observada nos diferentes horizontes dos perfis estudados (Figura 2). O quadro 2 foi obtido a partir da intensidade dos reflexos e dos teores de Si e Al extraídos por ataque sulfúrico (Coelho \& VidalTorrado, 2003) e proporciona uma idéia do conteúdo

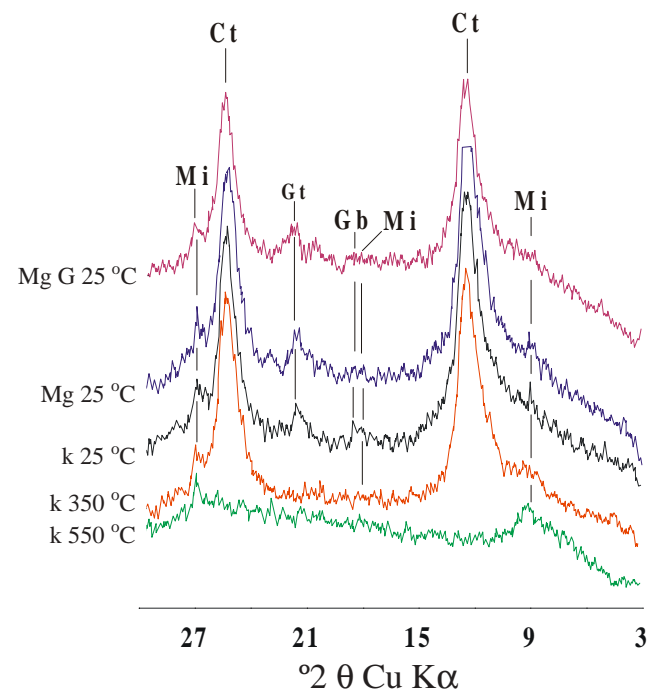

Figura 1. Difratogramas de raios-X da fração argila desferrificada referentes às glébulas petroplínticas (CC-N) do perfil P1. Minerais identificados: caulinita (Ct), mica (Mi), traços de gibbsita (Gb) e goethita (Gt).

Quadro 2. Conteúdo relativo(1) dos minerais silicatados e gibbsita na fração argila

Horizonte(2) $^{(2)}$ Profundidade $\frac{\text { Minerais }}{\text { Caulinita Mica Gibbsita }}$

\begin{tabular}{|c|c|c|c|c|}
\hline \multicolumn{5}{|c|}{$\mathrm{m}$} \\
\hline \multicolumn{5}{|c|}{ Perfil P1 } \\
\hline $\begin{array}{l}\text { A } \\
\text { E } \\
\text { Cc-S } \\
\text { Cc-N } \\
\text { Cf-S } \\
\text { Cf-N } \\
\text { Cr } \\
\text { Crg1 } \\
\text { Crg2 }\end{array}$ & $\begin{array}{l}0,00-0,10 \\
0,10-0,25 \\
0,25-0,45 \\
0,25-0,45 \\
0,45-0,55 \\
0,45-0,55 \\
0,55-1,16 \\
1,16-1,40 \\
1,40-1,80\end{array}$ & $\begin{array}{l}2 \\
2 \\
3 \\
2 \\
3 \\
2 \\
3 \\
3 \\
3\end{array}$ & $\begin{array}{l}1 \\
1 \\
1 \\
1 \\
1 \\
1 \\
2 \\
2 \\
2\end{array}$ & $\begin{array}{l}1 \\
1 \\
1 \\
1 \\
1 \\
0 \\
0 \\
0 \\
0\end{array}$ \\
\hline \multicolumn{5}{|c|}{ Perfil P2 } \\
\hline $\begin{array}{l}\text { A } \\
\text { E } \\
\text { Bt1 } \\
\text { Bt2 } \\
\text { Cc-S } \\
\text { CC-N } \\
\text { Cf } \\
\text { Cr } \\
\text { R }\end{array}$ & $\begin{array}{l}0,00-0,10 \\
0,10-0,26 \\
0,26-0,38 \\
0,38-0,60 \\
0,60-0,85 \\
0,60-0,85 \\
0,85-1,10 \\
1,10-1,64 \\
1,64-1,90\end{array}$ & $\begin{array}{l}1 \\
1 \\
3 \\
3 \\
3 \\
1 \\
2 \\
2 \\
1\end{array}$ & $\begin{array}{l}2 \\
1 \\
1 \\
1 \\
1 \\
1 \\
2 \\
2 \\
3\end{array}$ & $\begin{array}{l}1 \\
1 \\
1 \\
1 \\
1 \\
1 \\
1 \\
0 \\
0\end{array}$ \\
\hline
\end{tabular}

(1) Conteúdo relativo: 0 - não detectado, 1 - presente, 2 - moderadamente abundante, 3 - abundante. (2) Cc-S e Cf-S: matriz intergl ebular dos horizontes petroplíntico (Cc) e plíntico (Cf) respectivamente; Cc-N e Cf-N: nódulos dos horizontes $\mathrm{Cc}$ e $\mathrm{Cf}$ respectivamente; Cf: horizonte Cf do perfil P2. Amostra homogeneizada (nódulos + matriz). relativo dos minerais silicatados e gibbsita na fração argila. Observa-se que este último mineral está presente apenas em pequenas proporções e, principalmente, no solum e matriz interglebular (CcS), sugerindo que as condições gerais para estabilização dos minerais nestes solos são
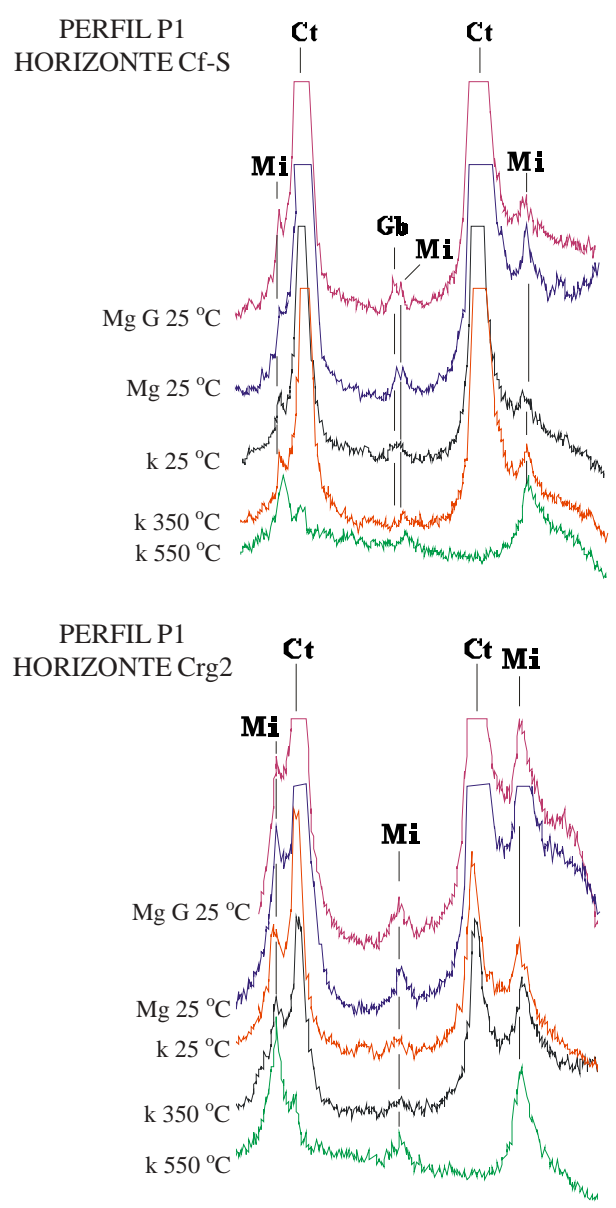

PERFIL P2

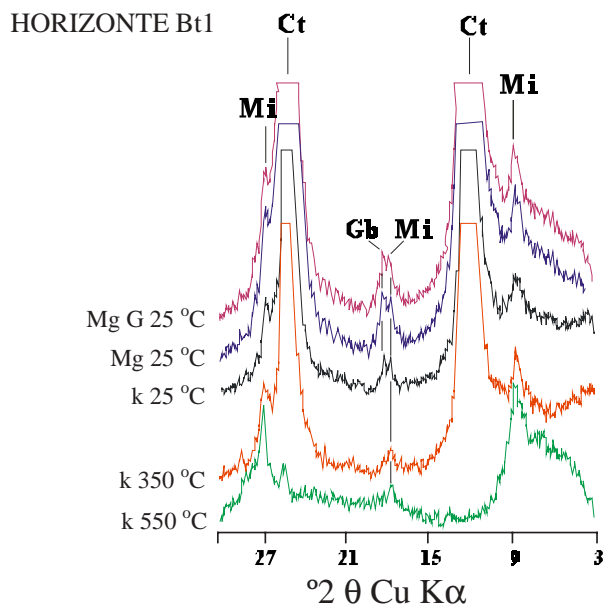

Figura 2. Difratogramas de raios-X da fração argila desferrificada referentes a alguns horizontes dos perfis estudados. Minerais identificados: caulinita (Ct), mica (Mi) e gi bbsita (Gb). 
favoráveis à manutenção da caul inita em detrimento da gibbsita, e por isso, este último encontra-se em pequenas proporções. Os el evados teores de areia fina e muito fina presentes em todos os horizontes (Quadro 3), a maioria deles contendo minerais primários intemperizáveis (Coelho, 1998), podem liberar Si na solução do solo, o suficiente para inibir a formação de minerais gibbsíticos.

\section{Mineralogia dos óxidos de ferro}

Hematita e goethita foram os únicos óxidos de ferro identificados com o tratamento das amostras (Figura 3). No entanto, o mineral anatásiotambém foi concentrado eidentificado em todos os horizontes e glébulas estudados (espaçamento $d=0,35 \mathrm{~nm}$; difratogramas do perfil P1 não mostrados).

O quadro 4 revela os conteúdos dehematita $(\mathrm{Hm})$, goethita (Gt), bem como o val or R ( $\mathrm{Hm} / \mathrm{Hm}+\mathrm{Gt})$ eo grau de substituição isomórfica nos óxidos de ferro (SI Gt eSI H m). Diferentes métodos foram utilizados no cálculo da substituição isomórfica em Al, pois, além da possibilidade de comparação, também contribuem para a maior segurança nos resultados, uma vez que todos apresentam diferentes fontes de erro (Barral Silva, 1987), bem como promovem uma grande variação nos resultados quando as amostras constituem-se de uma mistura de hematita e goethita (Shadfan et al., 1985).

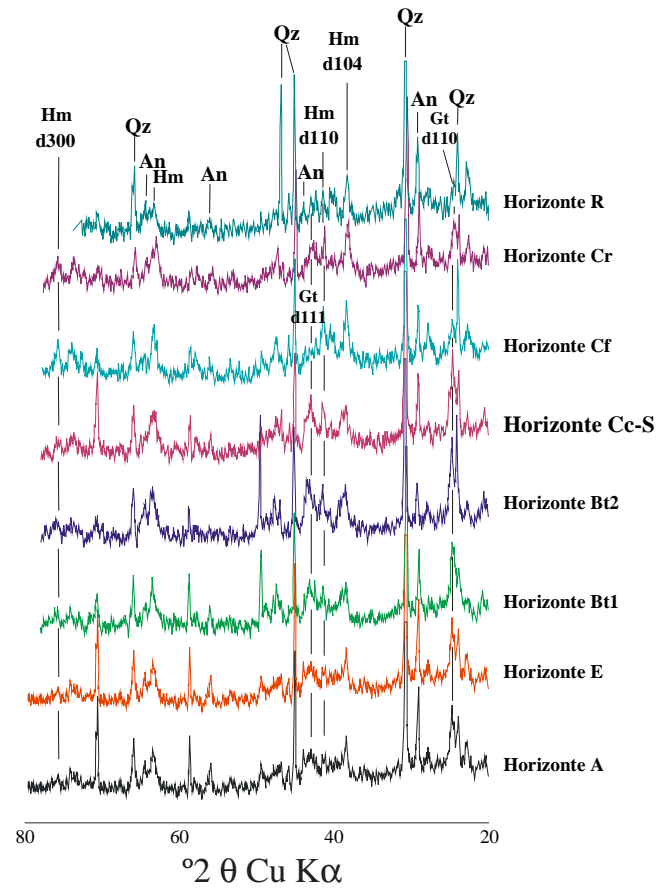

Figura 3. Difratogramas dos óxidos de ferro referentes a todos os horizontes do perfil P2, indicando os principais minerais com seus espaçamentos interplanares. Minerais identificados: hematita (Hm), goethita (Gt), anatásio (An) e quartzo (Qz).

Quadro 3. Análise granulométrica correspondente à fração menor que $\mathbf{2}$ mm

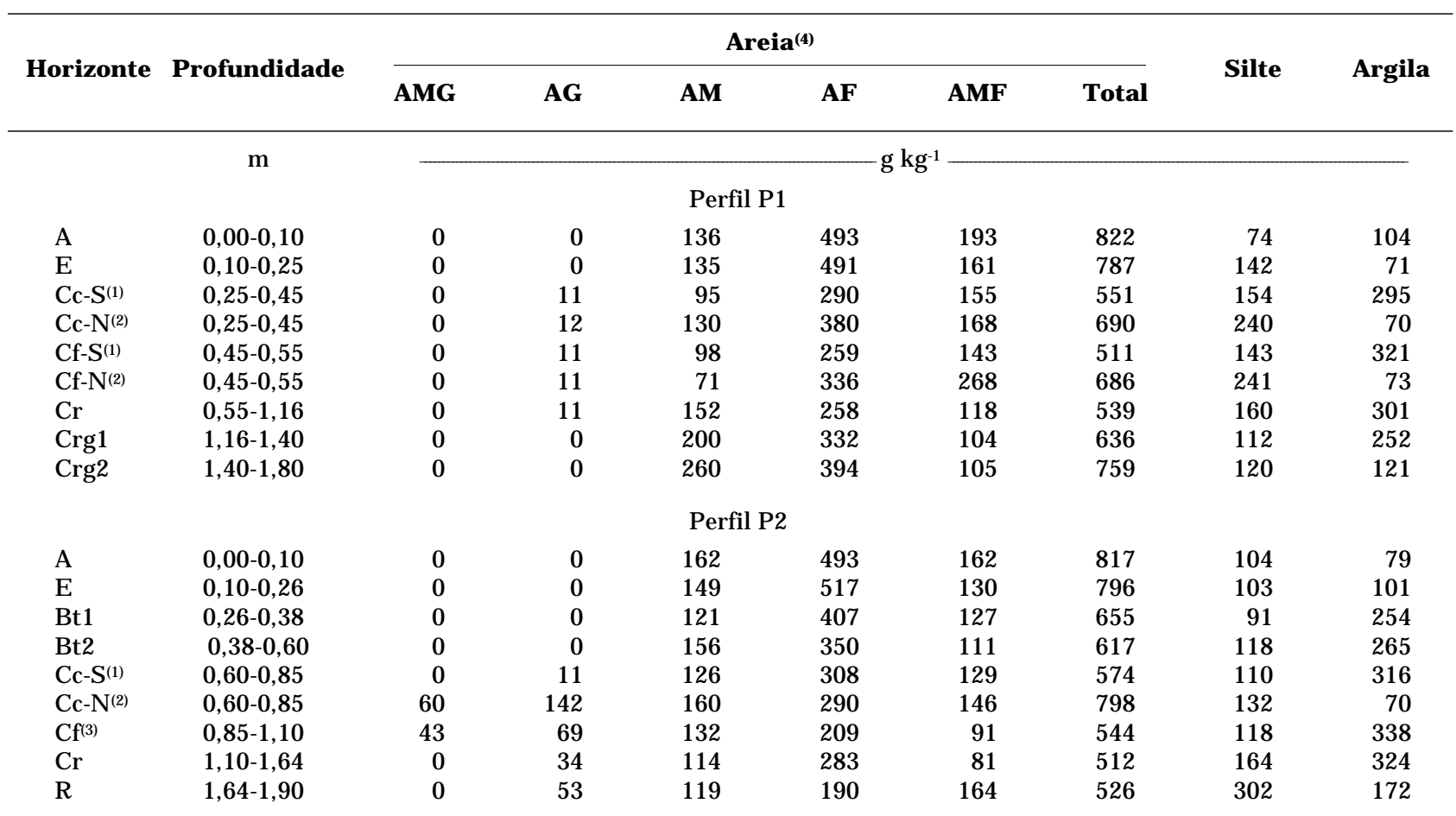

(1) Cc-S e Cf-S: matriz interglebular dos horizontes petroplíntico (Cc) e plíntico (Cf) respectivamente. (2) Cc-N e Cf-N: nódulos dos horizontes Cc e Cf respectivamente. ${ }^{(3)} \mathrm{Cf}$ : horizonte Cf do perfil P2. Amostra homogeneizada (nódulos + matriz). ${ }^{(4)}$ AMG: areia muito grossa; AG: areia grossa; AM: areia média; AF : areia fina; AMF : areia muito fina. 


\section{Quadro 4. Valores de Hematita (Hm), Goethita (Gt), R (Hm/Hm + Gt) e de substituição isomórfica de ferro por alumínio na $\mathrm{Hm}$ (SIHm) e Gt (SIGt) determinados por diferentes procedimentos}

\begin{tabular}{|c|c|c|c|c|c|c|c|c|}
\hline Horizonte & Profundidade & Hm & Gt & $\mathbf{R}$ & SIGt DRX(1) & SIHm DR X'(2) & SIGt química(3) & SIOx química ${ }^{(4)}$ \\
\hline & $\mathrm{m}$ & - & -1 & $\%$ & 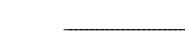 & $\mathrm{cmol}_{\mathrm{C}}$ & ${ }_{\mathrm{c}} \mathrm{Al} \mathrm{mol}{ }^{-1}$ & - \\
\hline \multicolumn{9}{|c|}{ Perfil P1 } \\
\hline$A$ & $0,00-0,10$ & 2,4 & 6,9 & 26 & 14 & 10 & 25 & 14 \\
\hline $\mathrm{E}$ & $0,10-0,25$ & 1,3 & 12,5 & 10 & 19 & 7 & 26 & 15 \\
\hline Cc-S & $0,25-0,45$ & 15,9 & 56,0 & 22 & 8 & 7 & 10 & 5 \\
\hline $\mathrm{Cc}-\mathrm{N}$ & $0,25-0,45$ & 195,9 & 148,4 & 57 & 10 & 5 & 5 & 3 \\
\hline Cf-S & $0,45-0,55$ & 14,6 & 57,6 & 20 & 23 & 4 & 16 & 9 \\
\hline Cf-N & $0,45-0,55$ & 106,2 & 131,4 & 45 & 12 & 2 & 8 & 4 \\
\hline $\mathrm{Cr}$ & $0,55-1,16$ & 23,8 & 35,5 & 40 & 18 & 6 & 11 & 6 \\
\hline Crgl & $1,16-1,40$ & 16,0 & 22,7 & 41 & $\mathrm{nd}(5)$ & 7 & 14 & 7 \\
\hline Crg2 & $1,40-1,80$ & 7,0 & 9,0 & 44 & 11 & 7 & 2 & 1 \\
\hline \multicolumn{9}{|c|}{ Perfil P2 } \\
\hline$A$ & $0,00-0,10$ & 1,7 & 9,6 & 15 & 15 & 7 & 14 & 7 \\
\hline $\mathrm{E}$ & $0,10-0,26$ & 2,9 & 11,0 & 21 & 12 & 3 & 14 & 7 \\
\hline Bt1 & $0,26-0,38$ & 5,4 & 22,9 & 19 & 30 & 13 & 20 & 11 \\
\hline Bt2 & $0,38-0,60$ & 13,3 & 37,8 & 26 & 22 & 8 & 15 & 8 \\
\hline Cc-S & $0,60-0,85$ & 12,7 & 45,9 & 22 & 19 & 10 & 10 & 5 \\
\hline Cc-N & $0,60-0,85$ & 272,5 & 139,3 & 66 & 8 & 3 & 5 & 3 \\
\hline $\mathrm{Cf}$ & $0,85-1,10$ & 72,2 & 64,8 & 53 & 12 & 3 & 4 & 2 \\
\hline $\mathrm{Cr}$ & $1,10-1,64$ & 22,8 & 41,4 & 35 & 6 & 1 & 1 & 1 \\
\hline $\mathrm{R}$ & $1,64-1,90$ & 49,0 & 14,9 & 77 & 25 & 5 & 12 & 5 \\
\hline
\end{tabular}

(1) SIGt DRX: substituição isomórfica do Fe por Al na goethita, determinada por difração de raios-X. ${ }^{(2)}$ SIHm DRX: substituição isomórfica do Fe por Al na hematita, determinada por difração de raios-X. ${ }^{(3)}$ SIGt química: substituição isomórfica na goethita determinada quimicamente segundo a expressão (Guillet \& J eanroy, 1985): Al cmol c mol-1 $=\frac{\left(\mathrm{Al}_{\mathrm{d}}-\mathrm{Al}_{\mathrm{o}}\right) / 27 \times 100}{\left(\mathrm{Al} \mathrm{l}_{\mathrm{d}}-\mathrm{Al}_{\mathrm{o}}\right) / 27+(\mathrm{Fed}-\mathrm{Feo}) / 55,8}$

(4) SIOx química: substituição isomórfica nos óxidos de ferro $(\mathrm{Hm}+\mathrm{Gt})$, determinada segundo a expressão (Shadfan et al., 1985):

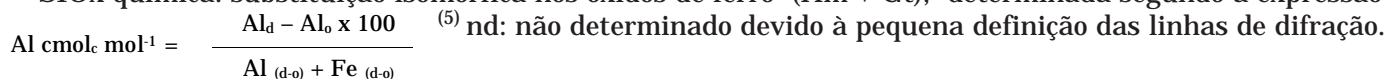

I números trabalhos têm tratado da substituição isomórfica de Fe por Al nos óxidos deferro em perfis plínticos e petroplínticos, evidenciando que goethita e hematita podem incorporar grandes conteúdos de alumínio na sua estrutura (Ambrosi \& Nahon, 1986; Trolard \& Tardy, 1989). Esses dados, complementados com o estudo de outras variáveis, apresentam um grande interesse aos estudos de gênese dos solos e materiais associados, uma vez que podem refletir os ambientes nos quais foram formados, bem como podem ser utilizados como indicadores dos processos pedogenéticos (Fitzpatrick \& Schwertmann, 1982).

Neste trabalho, os valores de SIGt abaixo de $15 \mathrm{cmol}_{\mathrm{C}} \mathrm{Al} \mathrm{mol}{ }^{-1}$ nas glébulas petroplínticas (Cc-N) indicam que sua origem está associada a condições hidromórficas, tal como afirmam Fitzpatrick \& Schwertmann (1982), embora, atualmente, ocorram em solos bem drenados. Segundo os autores, em ambientes hidromórficos, o ferro mobiliza-se preferencialmente nas formas reduzidas $\left(\mathrm{Fe}^{2+}\right)$, enquanto o alumínio não tem capacidade de trocar de valência, razão por que sua mobilidade não é afetada pelas variações das condições de redox que se produzem nos meios de hidromorfia parcial. O ferro ferroso $\left(\mathrm{Fe}^{2+}\right)$ move-se até às zonas do sol o que apresentam maior aeração, como, por exemplo, os macroporos situados entre os fragmentos de rochas dos horizontes saprolíticos aqui estudados, onde se produziriam sua precipitação e formação das glébulas, sem que existissem poucas fontes de alumínio, ou nenhuma, na sua proximidade. Além disso, a reação ligeiramente alcalina dos solos hidromórficos faz com que o elemento não esteja disponível para incorporação nos óxidos de ferro (Fitzpatrick \& Schwertmann, 1982).

Examinando o quadro 4, observa-se que os valores de SIGt no solum, saprolito e matriz interglebular determinada por DRX variaram de 6 a $30 \mathrm{cmol}_{\mathrm{c}} \mathrm{Al} \mathrm{mol}-1$, enquanto os valores de $\mathrm{SIHm}$ variaram de 1 a 13. Essas variações refletem as condições particulares dos horizontes durante a gênese dos óxidos de ferro e evolução dos solos e nódulos analisados. Nota-se que os níveis de substituição em Al na goethita da matriz intergl ebular (Cc-S) dos perfis são maiores que nas gl ébulas, bem como os horizontes texturais do perfil P2 mostram os maiores conteúdos de goethita aluminosa. Tais resultados indicam uma ampla disponibilidade de alumínio no ambiente durante a formação dos óxidos de ferro, uma vez que também 
a hematita encontra-se mais aluminosa na matriz Cc-S do perfil P2 e nos horizontes texturais Bt1 e Bt2. O maior valor deSI Gt no horizonte Bt1 (perfil P2) correspondeao maior val or deSI Hm, mostrando uma formaçãosi multânea dos óxidos (Gt e Hm) neste horizonte, embora o alumínio possa estar disponível em proporções similares em diferentes épocas de formação dos minerais hematíticos quando comparados aos goethíticos.

A camada $R$ do perfil P2 também apresenta um el evado conteúdo de SIGt. No entanto, hematita é relativamente pouco aluminosa, sugerindo, para o caso da goethita, uma formação contemporânea do mineral em virtude da elevada liberação do Al provindo da desestruturação da caulinita, pelo mecanismo de ferrólise. Este último processo foi constatado e discutido por Coel ho \& Vidal-Torrado (no prelo) para os horizonte $\mathrm{Cr}$ e camada $\mathrm{R}$ do solo analisado. Os maiores teores trocáveis de $\mathrm{Al}^{3+}$ nesta camada corroboram esses resultados (Quadro 5).

Considerando o mineral hematítico, os menores val ores de substituição isomórfica evidenciam uma origem pretérita para uma parte deste mineral na camada $\mathrm{R}$, anterior à formação da goethita e em condições pedoambientais de menor disponibilidade de Al. Essa mesma interpretação éauferida para os horizontes saprolíticos do perfil P 1 e possibilita uma explicação parcial dos elevados conteúdos de hematita nessas porções inferiores do perfil, uma vez que as condições atuais são favoráveis à formação de minerais oxídicos hidratados. A maior umidade e os baixos val ores de pH nesses horizontes ecamada (Quadro 5) propiciam a formação de goethita secundária (mineral hidratado) em detrimento da hematita (mineral desidratado), conformesugestões deKämpf \& Schwertmann (1983). No entanto, esses mesmos autores, citando o trabalho de Nalovic (1974), afirmam que outros metais, tais como Mn e $\mathrm{Cu}$, podem coprecipitar com ferridrita, precursor natural da hematita, retardando sua transformação para goethita e hematita, em favor da formação isolada dehematita. Assim, os el evados conteúdos de Mn e Cu na rocha do P2 (Quadro 5) também podem ser parcialmente responsabilizados pel o el evado valor da relação R nesta porção do perfil, principalmente quando se considera a forma pouco cristalina dos minerais demanganês, tal comoevidenciado nos dados de dissol uções seletivas (Quadro 5).

Dos resultados e discussões enunciados, propõese que parte da hematita formou-se sob condições de maiores potenciais de oxidação nos saprolitos e rocha do P2, quando o nível do lençol freático supostamente encontrava-se em cotas inferiores às atuais, possibilitando a desidratação da ferridrita para formas cristalinas de hematita (Kämpf \& Schwertmann, 1983). No entanto, as mobilizações

Quadro 5. Valores de $\mathrm{pH}$ em $\mathrm{H}_{2} \mathrm{O}$ e $\mathrm{KCl}$, alumínio trocável $\left(\mathrm{Al}^{3+}\right)$, cobre total $(\mathrm{Cu})$, manganês (Mn) livre e amorfo dos perfis $\mathrm{P} 1$ e $\mathrm{P} 2$

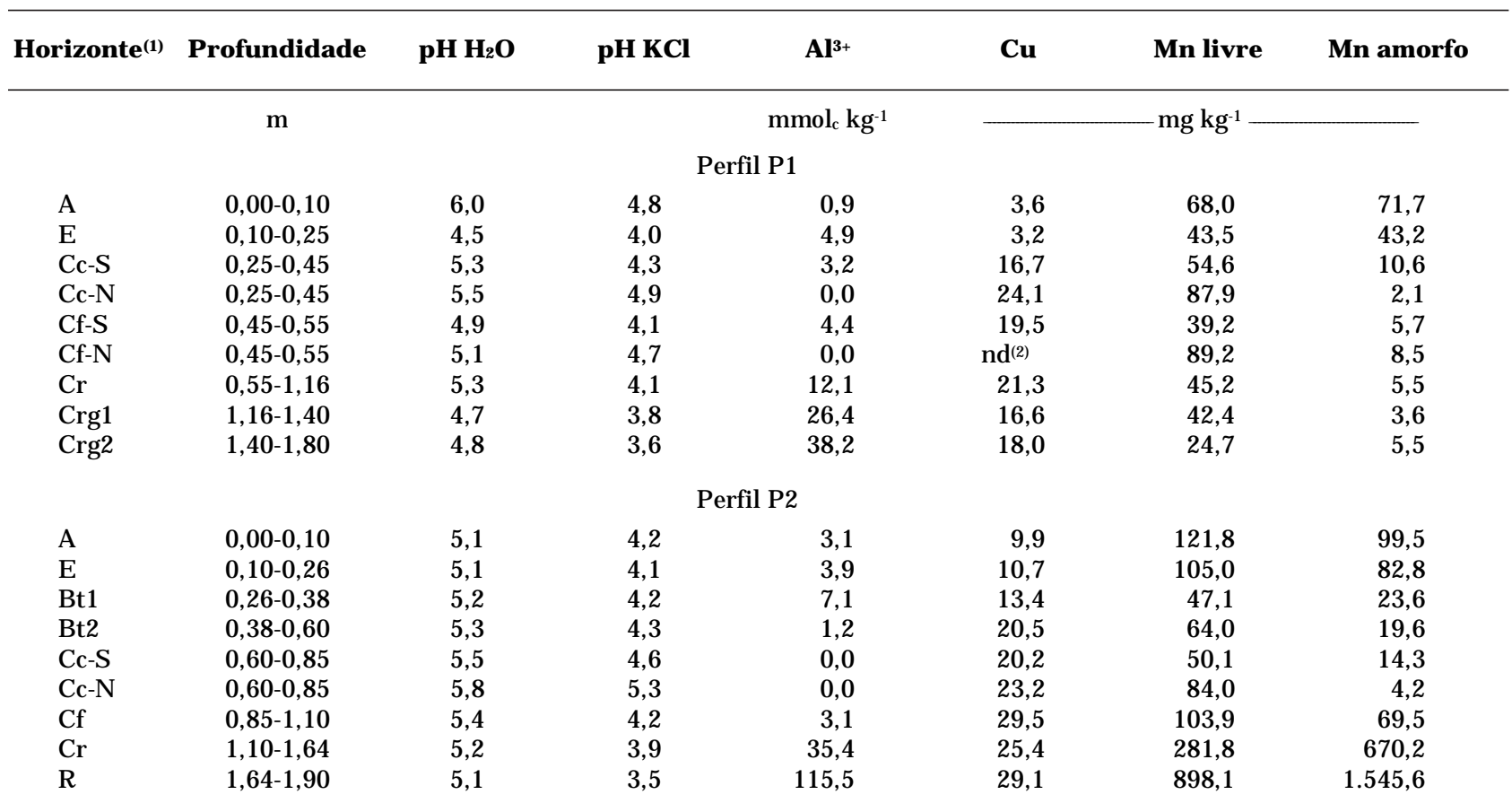

(1) Cc-S e Cf-S: matriz interglebular dos horizontes petroplíntico (Cc) e plíntico (Cf) respectivamente; Cc-N e Cf-N: nódulos dos horizontes Cc e Cf respectivamente; Cf: horizonte Cf do perfil P2. Amostra homogeneizada (nódulos + matriz). ${ }^{(2)}$ nd: não-determinado. 
atuais de ferro, principalmente provenientes da degradação das glébulas petroplínticas, tal como constatado por Coel ho (1998), são responsáveis pela formação de goethita aluminosa nas porções inferiores dos perfis, tanto favorecida pela maior umidade, como pela presença e maior disponibilidade de Al trocável. Essas mobilizações possibilitaram a formação atual de al guma hematita nos horizontes e camada com el evados conteúdos de $\mathrm{Mn}$, bem como nos macroporos dos horizontes saprolíticos e rocha, onde a atividade da água é baixa.

O conteúdo dos óxidos de ferro na fração argila evidencia que as glébulas petroplínticas do perfil P2 são mais ricas nesses minerais oxídicos em relação às demais glébulas e horizontes. No entanto, observa-se que os óxidos ocupam apenas uma pequena parcel a da fração argila dos sol os e glébulas, indicando que grande parte desta fração é dominada por caulinita. Anatásio, ilita e pequenos conteúdos de gi bbsita complementam a mi neral ogia das argilas dos materiais estudados.

Analisandoa relação R, notam-seos baixos val ores relativos para as matrizes interglebulares dos horizontes plínticos e petroplínticos (em torno de $20 \%$ ), quando comparados aos demais horizontes e glébulas estudados. Isso revela maior umidade nestes horizontes nodulares, favorecendo a formação de goethita. A maior percentagem de argila como matriz de materiais cascal hentos (nódulos) de diferentes diâmetros, bem como a descontinuidade dos poros na transição entre o horizonte petroplíntico e o solum acima, possibilita a permanência da água neste horizonte, uma vez quesua retenção é maior ea perda por evaporação reduzida. Essa hidratação promove a desestabilização da associação entre a caulinita remanescente nas glébulas e a hematita, estáveis em meio pouco hidratado e oxigenado (Beauvais \& Tardy, 1993), estabel ecendo condi ções adequadas à degradação das glébulas, bem como à mobilização dos el ementos liberados, princi pal mente $\mathrm{Fe}^{2+}$, aos horizontes saprolíticos e rocha abaixo. Evidências macro e mi cromorfológi cas da degradação atual das glébulas petroplínticas eli beração deferro, que é parcialmente precipitado nos horizontes inferiores do perfil P2, são apresentadas por Coelho et al. (2001).

Pela análise dos valores de $R$, nota-se também que as glébulas petroplínticas dos perfis P1 eP2 são predominantemente hematíticas, embora el evados conteúdos de goethita estejam presentes. Nas glébulas plínticas, há um predomínio de goethita na sua constituição, ocorrendo também a hematita em proporções consideráveis. Esses resultados concordam com a formação mais recente dessas glébulas plínticas em relação às petroplínticas, uma vez quea ferruginização é primeiramente goethítica nos estádios iniciais de formação e torna-se progressivamente hematítica durante os processos de oxidação e endurecimentodessematerial (Beauvais \& Colin, 1993).

\section{Microscopia de varredura e microanálise pontual}

As observações submicroscópicas de amostras indeformadas e selecionadas das glébulas possibilitaram complementar a caracterização mineralógica desses materiais, bem como elucidar alguns dos mecanismos envolvidos na sua gênese.

Dentre os minerais identificados nas glébulas plínticas e petroplínticas com as diferentes análises realizadas, a mi croscopia el etrônica ea mi croanálise possibilitaram a identificação de feldspatos potássicos e sódicos, cerianita e ilmenita. Dentre eles, os feldspatos potássi cos são os mais comuns e mostram-seem diferentes estádios deintemperismo, predominando os fortemente intemperizados. A figura 4 mostra em detal hes omineral se decompondo. Duas interpretações podem ser inferidas desta figura: a primeira refere-se ao desenvolvimento de cavidades de dissolução, as quais podem ser preenchidas por outros materiais na evolução das glébulas; a segunda elucida o desenvol vimento de al guns minerais gi bbsíticos no interior dos nódulos. Nota-se a presença da gibbsita acima e nas extremidades do feldspato, revelando uma origem autigênica, proveniente da degradação direta do mineral fel dspático.

Minerais primários, tais como fel dspatos e micas, foram indicados por muitos autores como constituintes comuns de nódulos e concreções ferruginosas (Beauvais \& Roquin, 1996; Debaveye \& Dapper, 1987). McF arlane (1976) afirma que os nódulos provenientes da oscilação do lençol tem a habilidade de fossilizar internamente o estado de intemperismo do saprolito, possibilitando, assim, a manutenção de minerais primários no seu interior. Portanto, a presença constante desses minerais no interior das glébulas petroplínticas estudadas evidencia sua formação em horizontes saprolíticos, bem como sugere a participação do lençol freático na gênese desses materiais.

A figura 5 revela a presença do mineral cerianita e os elementos Co e $\mathrm{Mn}$ associados, os quais são constituintes de al gumas glébulas que apresentaram o maior conteúdo de manganês dentre todas as glébulas do perfil (Coelho \& Vidal-Torrado, 2000), localizadas predominantemente na base do horizonte petroplíntico do P2.

A presença de cerianita na fração argila não é comum nas glébulas estudadas. Sua ocorrência aparece como um fenômenolocal esempreassociada aos el ementos cobal to e manganês. Outros autores também identificaram essa mesma correlação entre os elementos e evidenciaram a segregação de minerais raros (cerianita) durante a ferrugi nização na gênese de nódulos ferruginosos (Beauvais \& Colin, 1993; Beauvais \& Roquin, 1996).

Caulinita éúnico mineral silicatado presenteem proporções consideráveis dentro das lateritas 


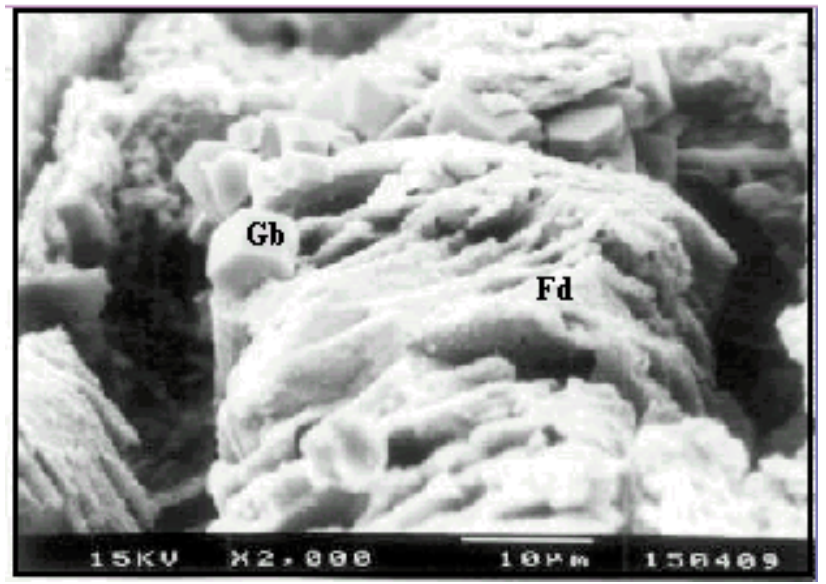

Figura 4. I magem de MEV exibindo um feldspato potássico ( $\mathrm{Fd}$ ) e gibbsita (Gb) no interior de uma glébula petroplíntica (perfil P2). Nota-se o avançado estádio de dissolução do feldspato, originando gibbsita in situ após remoção dos constituintes mais solúveis.

(Alexander \& Cady, 1962) e, freqüentemente, mostra uma história compl exa, caracterizada por dissoluções e neoformação durante o desenvol vimento dos perfis (Ambrosi et al., 1986). Basicamente, esse mineral foi identificado no interior das glébulas aparentando dois ti pos morfológi cos distintos. O primeiro mostra macrocristais de caulinita individualizados (aproximadamente $10 \mu \mathrm{m}$ ), bem cristalinizados e orientados (Figura 6). Possivelmente, essa orientação das argilas está associada à sua mobilização (argiluviação) e deposição durante a gênese dos nódulos (caulinita de primeira geração). O segundo tipo revela cristais que aparentam uma menor cristalinidade, em virtude de morfologia com bordas arredondadas, e mostram uma associação em forma de "sanfona" (Figura 7). São de menores dimensões (aproximadamente $5 \mu \mathrm{m}$ ) e estão associados às porções das glébulas visualmente identificadas como pequenos volumes esbranquiçados no seu interior. Possivelmente, referem-se às dissol uções atuais, potencialmente relacionadas com a neoformação de caulinita (caulinita de segunda geração) nas porosidades geradas com a dissolução de outros minerais (quartzo e feldspato) ou da própria caulinita.

Os grãos de quartzo foram os principais constituintes das glébulas, perfazendo, aproximadamente, $60 \%$ de sua constituição mineralógica (Coel ho et al., 2001). Em geral, mostram-se fortemente intemperizados, originando figuras típicas de dissolução na sua superfície (Flageollet, 1981), bem como poros na matriz argi losa onde estão insertos, denominados cavidades de dissolução (Muller \& Bocquier, 1986), as quais podem ser preenchidas por outros materiais que não óxidos de ferro (Leprun, 1981). As figuras 8 e 9 evidenciam a
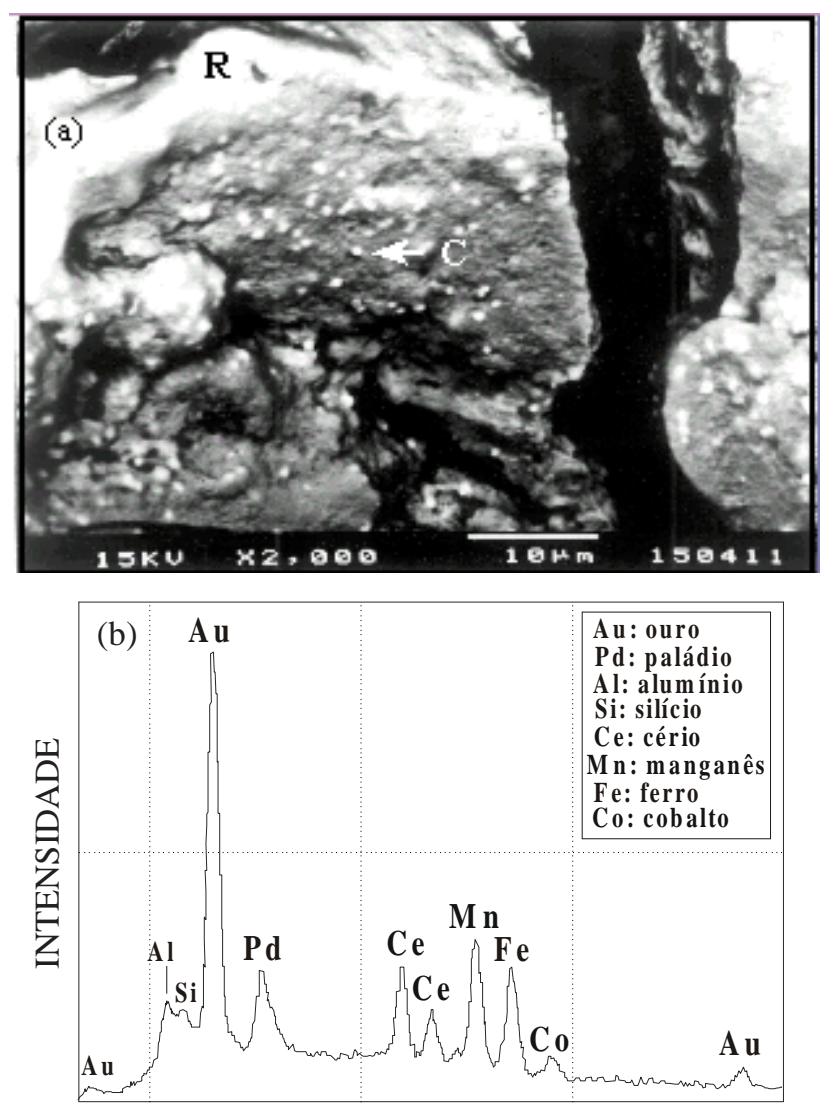

$\mathrm{E}, \mathrm{eV}$

Figura 5. Imagem de MEV do interior de uma glébula petroplíntica exibindo a presença de um "coating" ( $R$ ) de manganês recobrindo parcialmente um grão de quartzo. Cobalto e Cério estão associados em virtude de sua adsorsão nos óxi dos de Mn. 0 mi neral cerianita (C - glomérulos arredondados e de coloração branca) aparece precipitado na superfície do grão de quartzo (a). Análise química semiquantitativa em espectro EDS do "coating" de manganês (b).

dissolução do mineral quartzoso no interior da cavidade de dissolução, bem como seu preenchimento com macrocristais de gibbsita.

Resultados similares foram encontrados por Bourman et al. (1987), argumentando quea presença de gibbsita nessas cavidades é indício de condições extremamenteintemperizadas, ambientes ácidos em que a drenagem livre pode promover uma intensa lixiviação dos solutos. Essas condições ocorrem, possivelmente, em micros sítios no interior das glébulas, favorecendo a mobilização de Al a curtas distâncias e sua deposição nas cavidades de dissolução na forma de gibbsita secundária, assim como a completa lixiviação da sílica, a qual irá compor a estrutura dos minerais cauliníticos, principalmente na rocha do perfil P2, tal como evidenciado por Coel ho \& Vidal-Torrado (2003) para 


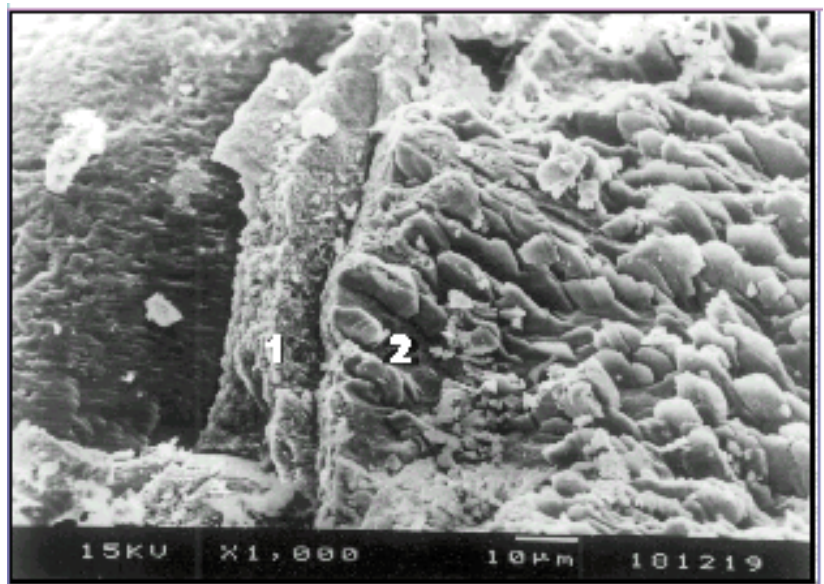

Figura 6. Fotomicrografia de MEV exibindo plaquetas individuais de caulinita macrocristalina no interior de uma glébula petroplíntica (perfil P1). Há duas deposições ou camadas recobrindo o grão de quartzo. A primeira (1) é constituída predominantemente de óxidos de ferro, com menores conteúdos de caulinita (espectro EDS não mostrados); a segunda (2) mostra macrocristais de caulinita orientados e bem cristalinizados inseridos numa matriz predominantemente oxídica, aparentando mobilização e deposi ção durante a gênese das glébulas.

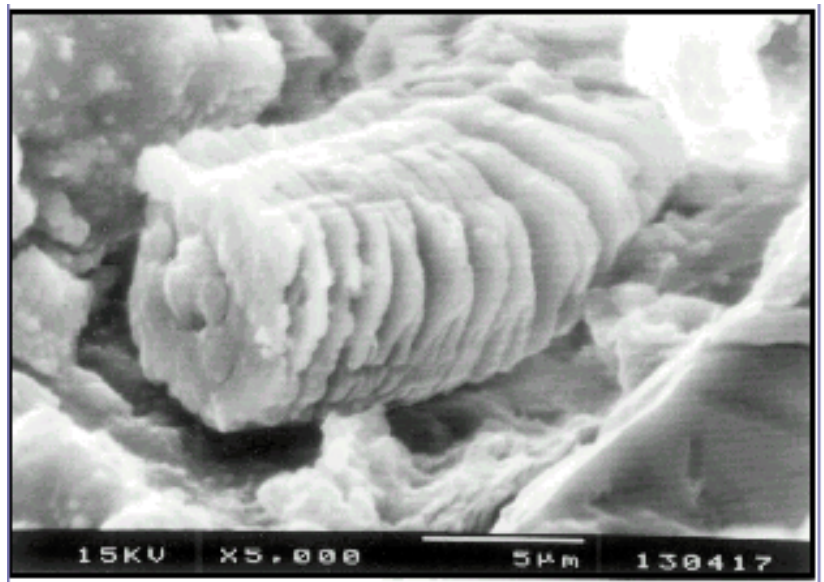

Figura 7. Fotomicrografia de MEV exibindo plaquetas de caulinita em forma de sanfona no interior de uma glébula petroplíntica (perfil P 1). Notam-se as bordas arredondadas, sugerindo inci piente estádio de decomposição.

a área estudada. A fonte primária desses minerais deve estar relacionada com a decomposição dos minerais fel dspáticos. Nota-se que o grão de quartzo não foi totalmente dissolvido eainda permanece no interior da cavidade de dissolução (Figura 8).

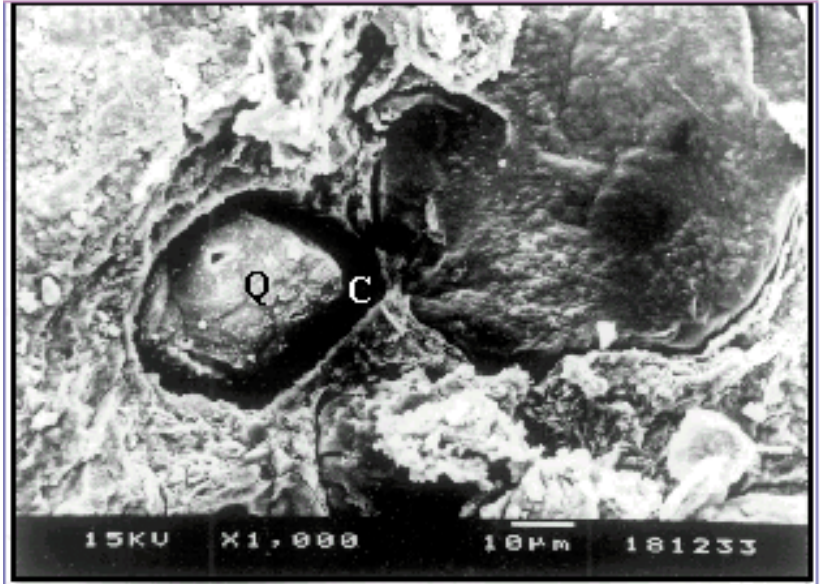

Figura 8. I magem de MEV evidenciando uma cavidade de dissolução de quartzo (C) no interior da glébula petroplíntica (perfil P2). Em maior aumento, observam-se abundantes figuras típicas de dissolução no mineral quartzoso (Q).

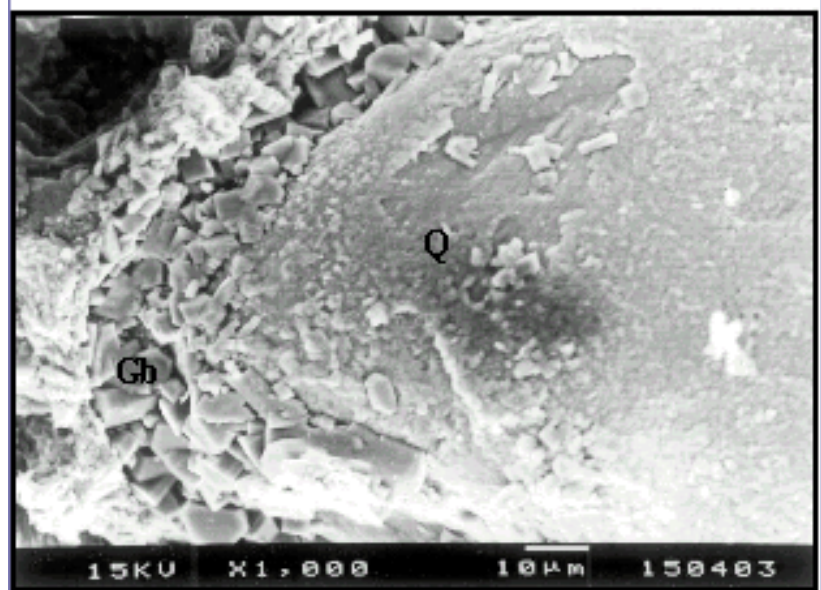

Figura 9. Fotomicrografia de MEV exibindo minerais de gibbsita (Gb) preenchendo a porosidade gerada na dissolução do grão de quartzo - Q (glébula petroplíntica do perfil P2).

\section{CONCLUSÕES}

1. Caulinita, hematita, goethita, mica, gibbsita e anatásiosão os principais constituintes mineralógicos da fração argila dos nódulos ferruginosos, assemelhando-se em constituição aos horizontes dos sol os estudados.

2. As frações areia e silte são dominadas por quartzo. No entanto, feldspatos potássicos foram encontrados em diferentes estádi os de intemperismo, predominando os fortemente intemperizados.

3. A presença constante desses minerais potássicos no interior das glébulas é a principal evidência da 
origem das petroplintitas associada à ferruginização dos horizontes saprolíticos. Outros minerais, como feldspato sódico, ilmenita e cerianita, também são componentes dos nódul os, embora menos expressivos.

4. O elemento do grupo das terras raras, cério (Ce), apareceu como precipitados concentrados (cerianita), e sempre associado ao manganês e cobal to no cerne de algumas glébulas enegrecidas por causa da presença do manganês.

5. Valores de substituição isomórfica de Fe por Al inferiores a $15 \mathrm{cmol}_{\mathrm{C}} \mathrm{Al} \mathrm{mol}-1$ nas glébulas petroplínticas apoiam a hipótese da influência do hidromorfismo na formação desses materiais; fato que, associado à presença constante de minerais alteráveis, consubstancia a sua formação, supostamente relacionada com a deposição do ferro na zona de vadosa durante a evolução da paisagem.

\section{LITE RATURA CITADA}

ALEXANDER, T.L. \& CADY, J.G. Genesis and hardening of laterite in soils. Washington, D.C., Soil Conservation Service, United States Department of Agriculture, 1962. 90p. (Technical Bulletin, 1282)

AMBROSI, J.P. \& NAHON, D. Petrological and geochemical differentiation of lateritic iron crust profiles. Chem. Geol., 57:371-393, 1986.

AMBROSI, J.P.; NAHON, D. \& HERBILLON, A.J. The epigenetic replacement of kaol inite by hematite in laterite - petrographic evidence and the mechanisms involved. Geoderma, 37:283-294, 1986.

BARRAL SILVA, M.T. Estudio de las separaciones de hierro y manganeso en suelos y sedimentos de Galicia. Santiago, Facultad de Biología de la Universidad de Santiago de Compostela, 1987. 680p. (Tese de Doutorado)

BATISTA, M.A. \& SANTOS, M.C. Morfologia e gênese de dois sol os com plintita da Região Meio-N orte do Brasil. R. Bras. Ci. Solo, 9:287-296, 1995.

BEAUVAIS, A. \& COLIN, F. Formation and transformation processes of iron duricrust systems in tropical humid environment. Chem. Geol., 106:77-101, 1993.

BEAUVAIS, A. \& ROQUIN, C. Petrological differentiation patterns and geomorphic distribuition of ferricretes in Central Africa. Geoderma, 73:63-82, 1996.

BEAUVAIS, A. \& TARDY, Y. Degradation and dismantling of iron crusts under climatic changes in Central Africa. Chem. Geol., 107:277-280, 1993.

BOURMAN, R.P.; MILNES, A.R. \& OADES, J .M. Investigations of ferricretes and related surficial ferruginous materials in parts of southern and eastern Australia. Zeitschrift Geomorphologie. Supl., 64:1-24, 1987.

BROWN, G., ed. The x-ray identification and crystal structures of clay minerals. London, J arrold Sons, 1961. 544p.
BUURMAN, P.; LAGEN, B van \& VELTHORST; E.J . Manual for soil and water analysis. Wageningen, Backhuys Publihers Leiden, 1996. 314p.

CAMARGO, O.A.; MONIZ, A.C.; J ORGE, J .A. \& VALADARES, J .M.A.S. Métodos de análise química, mineralógica efísica de sol os do I nstituto Agronômico de Campinas. Campinas, Instituto Agronômico de Campinas, 1986. 94p. (Boletim Técnico, 106)

COELHO, M.R. Caracterização e gênese de ferricretes desenvolvidos do arenito Bauru, Formação Adamantina (Ka), no município de Pindorama (SP). Piracicaba, Escola Superior de Agricultura “Luiz de Queiroz", 1998. 233p. (Tese de Mestrado)

COELHO, M.R. \& VIDAL-TORRADO, P. Caracterização e gênese de perfis plínticos desenvol vidos de arenito do Grupo Bauru. I - Química. R. Bras. Ci. Solo, 27:483-494, 2003.

COELHO, M.R. \& VIDAL-TORRADO, P. Cério (Ce) em ferricretes nodulares desenvolvidos em solos da Formação Adamantina. Piracicaba. Sci. Agric., 54:329-336, 2000.

COELHO, M.R.; VIDAL-TORRADO, P. \& LADEIRA, F.S.B. Macro e micromorfologia de ferricretes nodulares desenvolvidos de arenito do Grupo Bauru, Formação Adamantina. R. Bras. Ci. Solo, 25:371-385, 2001.

DEBAVEYE, J . \& DAPPER, M. Laterite, soil and landform development in Kedah, Peninsular Malaysia. Zeitschrift Geomorphol. Supl., 64:145-161, 1987.

FITZPATRICK, R.W. \& SCHWERTMANN, U. Al- substituted goethite - An indicator of pedogenic and other weathering environments in South Africa. Geoderma, 27:335-347, 1982.

FLAGE OLLET, J.C. Aspects morphoscopiques et exoscopiques des quartz dans quel ques sols ferrallitiques de la région de Cechi (Côte d'Uvoire). Cahiers ORSTOM., série Pédol., 17:111-121, 1980-1981.

GUILLET, B. \& J EANROY, E. Note sur une methode chimique d'evaluation des substitutions alumineuses dans les oxydes et/ou oxyhydroxydes de fer. Sc. sol, 1:37-40, 1985.

INSTITUTO DE PESQUISA TECNOLÓGICA - IPT. Mapa Geológico do estado de São Paulo. Escala 1:500.000. São Paulo, 1981. v.1. 126p.

J ACKSON, M.L. Soil chemical analysis advanced course. 2.ed. Madison: published by the author, 1969. 895p.

KÄMPF, N. \& SCHWERTMANN, U. Goethite and hematite in a climosequence in southern Brazil and their application in classification of kaolinitic soils. Geoderma, 29:27-39, 1983.

KÄMPF, N. \& SCHWERTMANN, U. The 5-M-NaOH concentration treatment for iron oxides in soils. Clays Clay Miner., 30:401-408, 1982.

LEPRUN, J.C. Some principal features of ironcrusts in dry western Africa. In: INTERNATIONAL SEMINAR LATERITISATION PROCESSES, Trivandrum, 1979. Proceedings. New Delhi: Oxford \& IBH Publication, 1981. p.144-153.

McFARLANE, M.J. Laterite and Landscape. New York, Academic Press, 1976. 151p. 
MULLER, J.P. \& BOCQUIER, G. Dissolution of kaolinites and accumulation of iron oxides in lateritic ferruginous nodules: mineralogical and microstructural transformations. Geoderma, 37:113-136, 1986.

NALOVIC, L. Recherches géochimiques sur les éléments de transition dans les sols; Estude expérimentale de I cinfluence des éléments traces sur le comportmente du fer et I†évolution des composés ferriféres au cours de la pédogénése. Paris, ORSTON, 1974 (Tese de Doutorado)

NETTO, A.R. Influência da mineralogia da fração argila sobre propriedades físico-químicas de solos brasileiros. Viçosa, UniversidadeF ederal deViçosa, 1996. 144p. (TesedeMestrado)

NORRISH, K.\& TAYLOR, R.M. The isomorphous replacement of iron by aluminium in soil goethites. J. Soil Sci., 12:296306, 1961.

RESENDE, M.; BAHIA FILHO, A.F.C. \& BRAGA, J.M. Mineralogia da argila de Latossolos estimada por alocação a partir do teor total de óxidos do ataque sulfúrico. R. Bras. Ci. Solo, 11:17-23, 1987.
SCHULZE, D.G. The identification of iron oxides by differential $\mathrm{x}$-ray diffaction and the influence of aluminum substitution on the structure of goethite. Weihenstephan, Universität München, 1982. 167p. (Tese de Doutorado)

SCHWERTMANN, U., FITZPATRICK, R.W., TAYLOR, R.M. \& LEWIS, D.G. The influence of aluminum on iron oxides. Part II: preparation and properties of Al-substituted hematites. Clays Clay Miner., 27:105-112, 1979.

SHADFAN, H.; DIXON, J.B. \& CALHOUN, F.G. Iron oxide properties versus strength of ferruginous crust and ironglaebules in soils. Soil Sci., 140:317-325, 1985.

SOARES, P.C.; LANDIM, P.M.B.; FÚLFARO, V.J . \& NETO SOBREIRO, A.F. Ensaio de caracterização estratigráfica do cretáceo no estado de São Paulo: Grupo Bauru. R. Bras. Geoci., 10:177-235, 1980.

TROLARD, $\mathrm{F} \&$ TARDY, $\mathrm{Y}$. A model of $\mathrm{Fe}^{3+-}$ caolinite, $\mathrm{Al}^{3+}$. goethite, $\mathrm{Al}^{3+}$ - hematite equilibria en laterites. Clay Miner., 24:1-21, 1989. 